\title{
A New Copper Acetate-Bis(oxazoline)-Catalyzed, Enantioselective Henry Reaction
}

\author{
David A. Evans, ${ }^{*}$ Daniel Seidel, Magnus Rueping, Hon Wai Lam, Jared T. Shaw, and \\ C. Wade Downey \\ Department of Chemistry and Chemical Biology, Harvard University, Cambridge, Massachusetts 02138 \\ Received July 18, 2003; E-mail: evans@chemistry.harvard.edu
}

The nitroaldol (Henry) reaction is an important carbonyl addition process that affords products that may be transformed into valuable building blocks. ${ }^{1}$ Therefore, it is not surprising that recent efforts have focused on the development of catalytic enantioselective reaction variants. The current contributions to this area have been highlighted by the recent studies of Shibasaki and Trost. ${ }^{2-5}$ The purpose of this Communication is to report a new catalyst system for the nitroaldol reaction (eqs 1,$2 ; \mathrm{M}=\mathrm{Cu}, \mathrm{X}=\mathrm{OAc}$ ). The basis for the current study was to identify a weakly Lewis acidic metal complex bearing moderately basic charged ligands $(\mathrm{X})$ that would facilitate the deprotonation of nitroalkanes (eq 1) as a prelude to the aldol addition process (eq 2). It was felt that divalent metal acetate-ligand complexes of the general structure A might meet these requirements because acetate has been employed as a Brønsted base in the racemic nitroaldol reaction. ${ }^{1}$

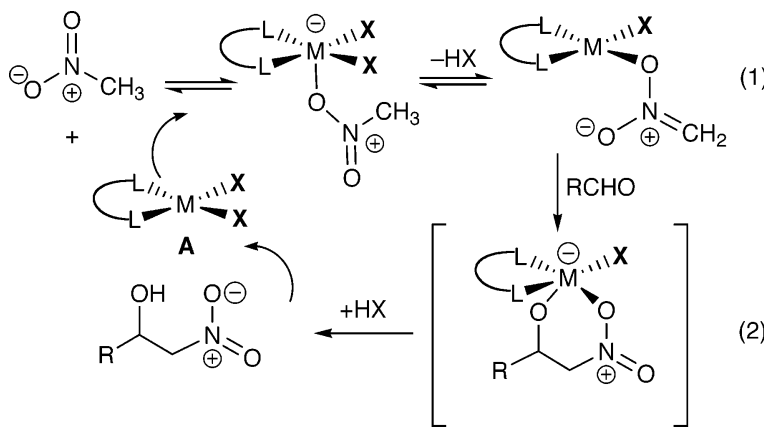

A series of divalent metal acetates in combination with chiral bidentate ligands were screened as enantioselective catalysts for the nitroaldol process. ${ }^{6,7}$ From this survey, bis(oxazoline) ${ }^{8}$ (box) complexes derived from $\mathrm{Cu}(\mathrm{OAc})_{2}$ emerged as promising catalyst candidates. The results from the ligand survey with this metal acetate are summarized in Table 1 . The five box ligands $(\mathbf{1 a}-\mathbf{d}$, 2) with the illustrated absolute configurations that were evaluated with $\mathrm{Cu}(\mathrm{OAc})_{2} \cdot \mathrm{H}_{2} \mathrm{O}$ afforded promising levels of enantioselection (entries 1-5). ${ }^{8,9}$ In each instance, the reactions carried out at ambient temperature were complete within $24 \mathrm{~h}$. From this comparison, the indabox ligand $\mathbf{2}$ proved to be the ligand of choice, ${ }^{9}$ providing the nitro alcohol product in $74 \%$ ee (Table 1, entry 5). With ethanol as the solvent (Table 1, entry 6), the nitro alcohol product was isolated in $81 \%$ ee. Further optimization of this process showed that the reaction may be performed with lower catalyst loadings (1-5 mol \%), while the use of 10 equiv of nitromethane was found to be sufficient for the reaction to proceed to completion. Reaction concentrations could also be increased to as high as 1.0 $\mathrm{M}$ with no change in enantioselectivity. $\mathrm{Cu}$ (II) carboxylate structure was also evaluated with ligand $\mathbf{2}$, and it was concluded that this catalyst variable is subordinate to ligand architecture. ${ }^{10}$ In all instances, the only side reaction observed in these reactions was the accompanying dehydration product.
Table 1. Ligand Survey of the Henry Reaction (eq 3$)^{a}$
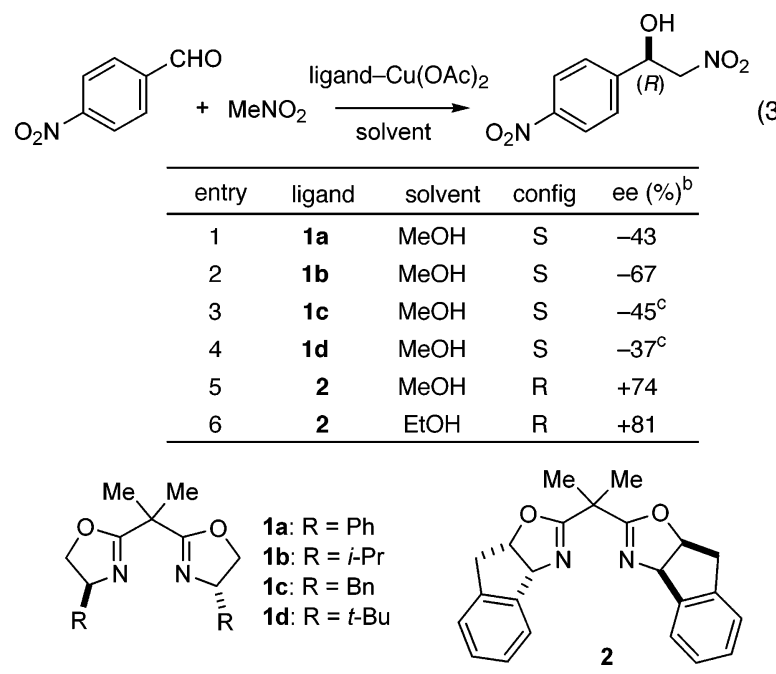

${ }^{a}$ All reactions were performed at room temperature on a $0.33 \mathrm{mmol}$ scale with $15 \mathrm{~mol} \%$ of ligand and $13.5 \mathrm{~mol} \%$ of $\mathrm{Cu}(\mathrm{OAc})_{2} \cdot \mathrm{H}_{2} \mathrm{O}$ at a 0.1 $\mathrm{M}$ concentration using 55 equiv of nitromethane. Reactions were run in a screw-capped vial and were complete within $24 \mathrm{~h} .{ }^{b}$ Enantiomeric excess was determined by HPLC using a Chiracel OD-H column. ${ }^{c}$ Reaction did not go to completion within $24 \mathrm{~h}$.

With optimized conditions in hand, the scope of the reaction was explored (Table 2). In general, high enantiomeric excesses (87$94 \%$ ee) are observed at room temperature for aromatic aldehydes bearing either electron-withdrawing or electron-donating groups (entries 1-9). ${ }^{11}$ Aliphatic branched and unbranched aldehydes are also acceptable substrates, affording nitro alcohol adducts in good yields and enantioselectivities (entries 10-15, 90-94\% ee).

Reaction enantioselectivity can be further improved by lowering the temperature at the accompanying expense of increasing the reaction time. In one instance, the reaction in entry 1 was performed by mixing the reactants and storing the resulting solution at $0{ }^{\circ} \mathrm{C}$ for 10 days. Subsequent isolation afforded the corresponding aldol adduct in $81 \%$ yield and $96 \%$ ee. When the same reaction was carried out at $40{ }^{\circ} \mathrm{C}$, significant rate acceleration was noted with an accompanying decrease in the enantioselection to $79 \%$ and an increase in elimination byproduct. ${ }^{11}$

Large-scale reactions at minimal catalyst loading ( $1 \mathrm{~mol} \%)$ were also evaluated. In one instance, the reaction between 2-methoxybenzaldehyde and nitromethane (as shown in entry 3, Table 2) was performed on a $50 \mathrm{mmol}$ scale with $1 \mathrm{~mol} \%$ of catalyst loading at a $1.0 \mathrm{M}$ concentration. Following a reaction time of $56 \mathrm{~h}$, the resulting product 3c was isolated in $92 \%$ yield (94\% ee). Using the same reaction parameters, the nitro alcohol product $3 \mathrm{~m}$ resulting from a reaction of isobutyraldehyde (as in entry 13) was isolated in $93 \%$ yield and $91 \%$ ee (108 $\mathrm{h}$ reaction time). These results 
Table 2. Henry Reaction of Nitromethane with Various Aldehydes $^{a}$

$$
\mathrm{R}-\mathrm{CHO}+\mathrm{MeNO}_{2} \underset{\mathrm{EtOH}, \mathrm{rt}}{\stackrel{[(2) \mathrm{Cu}](\mathrm{OAC})_{2}}{\longrightarrow}} \stackrel{\overbrace{(R)}^{\mathrm{OH}}}{\mathrm{NO}_{2}}
$$

\begin{tabular}{clcccc}
\hline entry & \multicolumn{1}{c}{$\mathrm{R}$} & product & time $(\mathrm{h})$ & yield $(\%)^{b}$ & ee $(\%)^{c}$ \\
\hline 1 & $\mathrm{Ph}$ & $\mathbf{3 a}$ & 22 & 76 & 94 \\
2 & $2-\mathrm{MeC}_{6} \mathrm{H}_{4}$ & $\mathbf{3 b}$ & 42 & 72 & 93 \\
3 & $2-\mathrm{MeOC}_{6} \mathrm{H}_{4}$ & $\mathbf{3 c}$ & 27 & 91 & 93 \\
4 & $2-\mathrm{NOC}_{6} \mathrm{H}_{4}$ & $\mathbf{3 d}$ & 4 & 86 & 89 \\
5 & $2-\mathrm{ClC}_{6} \mathrm{H}_{4}$ & $\mathbf{3 e}$ & 15 & 88 & 91 \\
6 & $1-\mathrm{naphhthyl}$ & $\mathbf{3 f}$ & 15 & 66 & 87 \\
7 & $4-\mathrm{FC}_{6} \mathrm{H}_{4}$ & $\mathbf{3 g}$ & 45 & 70 & 92 \\
8 & $4-\mathrm{ClC}_{6} \mathrm{H}_{4}$ & $\mathbf{3 h}$ & 21 & 73 & 90 \\
9 & $4-\mathrm{PhC}_{6} \mathrm{H}_{4}$ & $\mathbf{3 i}$ & 20 & 70 & 91 \\
10 & $\mathrm{PhCH}_{2} \mathrm{CH}_{2}$ & $\mathbf{3 j}$ & 24 & 81 & 90 \\
11 & $i-\mathrm{Bu}$ & $\mathbf{3 k}$ & 48 & 86 & 92 \\
12 & $t-\mathrm{Bu}$ & $\mathbf{3 l}$ & 96 & 83 & 94 \\
13 & $i-\mathrm{Pr}$ & $\mathbf{3 m}$ & 48 & 86 & 94 \\
14 & $n-\mathrm{Bu}$ & $\mathbf{3 n}$ & 48 & 87 & 93 \\
15 & $c y c l o h e x y l$ & $\mathbf{3 o}$ & 48 & 95 & 93 \\
\hline
\end{tabular}

${ }^{a}$ All reactions were performed on a $1 \mathrm{mmol}$ scale with $5 \mathrm{~mol} \%$ of $\mathrm{Cu}(\mathrm{OAc})_{2} \cdot \mathrm{H}_{2} \mathrm{O}$ and $5.5 \mathrm{~mol} \%$ of ligand 2 at a $0.5 \mathrm{M}$ concentration using 10 equiv of nitromethane in ethanol. Reactions were run at room temperature in a screw-capped vial for the indicated time. ${ }^{b}$ Values are isolated yields after chromatographic purification. ${ }^{c}$ Enantiomeric excess was determined by HPLC using Chiracel OD-H, OJ-H, or AD columns.

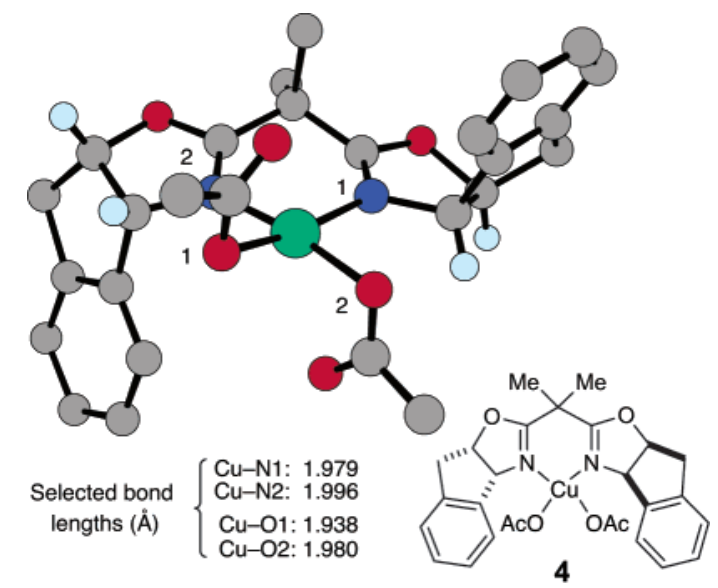

Figure 1. Crystal structure of complex 4.

suggest that catalyst loading in the $1 \%$ range might well be below the practical limit due to the long reaction times.

The X-ray structure of the chiral copper-ligand complex 4 shown in Figure 1 reveals the expected square planar geometry with the acetate carbonyl moieties oriented toward the vacant apical positions.

An attempt to rationalize how asymmetric induction is imparted from complex 4 begins with a statement of the impact of the JahnTeller (JT) effect on $\mathrm{Cu}$ (II) coordination. ${ }^{12}$ As illustrated in Figure 2, JT distortion of an octahedral $\mathrm{Cu}$ (II) complex creates four strongly coordinating and two weakly coordinating sites labeled red and blue, respectively. Addition of a bidentate ligand $\mathrm{L}_{2}$ affords a complex positioning the two cis-oriented strongly coordinating sites in the ligand plane and two trans-oriented weakly coordinating sites perpendicular to the ligand plane (Figure 2, eq 4). For those complexes that simultaneously bind both electrophile and nucleophile, the most reactive transition states should position the nucleophile perpendicular to the ligand plane, while the electrophile, for maximal activation, should be positioned in one of the more Lewis acidic equatorial sites in the ligand plane as illustrated for complex B. By the same argument, complex $\mathbf{D}$ should exhibit the
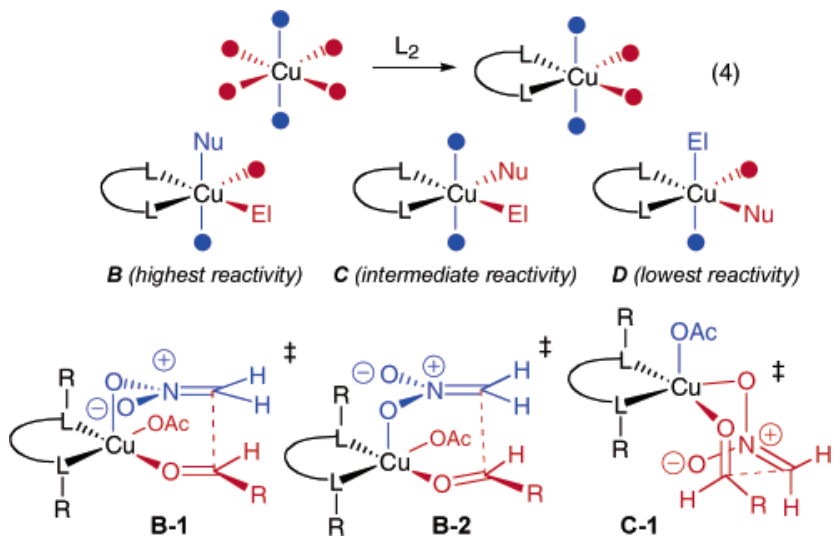

Figure 2. Plausible transition structures for the Henry reaction.

lowest reactivity (greatest stability). While transition states B-1 (boat), B-2 (chair), and C-1 (chair) all predict the observed sense of asymmetric induction, our predisposition is to favor $\mathbf{B}-\mathbf{1}$ on the basis of both steric and electronic considerations.

Further investigations into the mechanism and variants of this process are currently underway and will be reported in due course.

Acknowledgment. Support has been provided by the NSF and the NIH (GM 33328-18). D.S., M.R., and H.W.L. gratefully acknowledge Postdoctoral Fellowships from the Ernst Schering Research Foundation, the Deutsche Akademischer Austauschdienst (DAAD), and GlaxoSmithKline, respectively.

Supporting Information Available: Experimental procedures, spectral data, and stereochemical proofs for all compounds (PDF and CIF). This material is available free of charge via the Internet at http:// pubs.acs.org.

\section{References}

(1) For recent reviews, see: (a) Luzio, F. A. Tetrahedron 2001, 57, 915945. (b) Ono, N. The Nitro Group in Organic Synthesis: Wiley-VCH: New York, 2001. (c) Seebach, D.; Beck, A. K.; Mukhopadhyay, T.; Thomas, E. Helv. Chim. Acta 1982, 65, 1101-1133.

(2) (a) Sasai, H.; Suzuki, T.; Arai, S.; Shibasaki, M. J. Am. Chem. Soc. 1992 114, 4418-4420. (b) Shibasaki, M.; Yoshikawa, N. Chem. Rev. 2002 102, 2187-2209 and references therein.

(3) (a) Trost, B.; Yeh, V. S. C. Angew. Chem., Int. Ed. 2002, 41, 861-863. (b) Trost, B.; Yeh, V. S. C.; Ito, H.; Bremeyer, N. Org. Lett. 2002, 4 , $2621-2623$.

(4) For related studies, see: (a) Christensen, C.; Juhl, C.; Jørgensen, K. A. Chem. Commun. 2001, 2222-2223. (b) Christensen, C.; Juhl, C.; Hazell, R. G.; Jørgensen, K. A. J. Org. Chem. 2002, 67, 4875-4881. (c) Risgaard, T.; Gothelf, K. V.; Jørgensen, K. A. Org. Biomol. Chem. 2003, 153156.

(5) For enantioselective reactions mediated by chiral quaternary salts, see: (a) Ooi, T.; Doda, K.; Maruoka, K. J. Am. Chem. Soc. 2003, 125, 20542055. (b) Corey, E. J.; Zhang, F.-Y. Angew. Chem., Int. Ed. 1999, 38, $1931-1934$.

(6) Other metal salts were also screened in combination with ligand $\mathbf{2}$ and methanol as solvent, but were found to be inferior to $\mathrm{Cu}(\mathrm{OAc})_{2} \cdot \mathrm{H}_{2} \mathrm{O}$ : $\mathrm{Ni}(\mathrm{OAc})_{2} \cdot 4 \mathrm{H}_{2} \mathrm{O}, 30 \%$ ee; $\mathrm{Co}(\mathrm{OAc})_{2} \cdot 4 \mathrm{H}_{2} \mathrm{O}, 20 \%$ ee; $\mathrm{Mn}(\mathrm{OAc})_{2} \cdot 4 \mathrm{H}_{2} \mathrm{O}, 0 \%$ ee; $\mathrm{Zn}(\mathrm{OAc})_{2} \cdot 4 \mathrm{H}_{2} \mathrm{O}, 0 \%$ ee; $\mathrm{Mg}(\mathrm{OAc})_{2} \cdot 4 \mathrm{H}_{2} \mathrm{O}, 0 \%$ ee.

(7) Interestingly, $\mathrm{CuF}_{2}$, when used in place of $\mathrm{Cu}(\mathrm{OAc})_{2} \cdot \mathrm{H}_{2} \mathrm{O}$, gave very similar results ( $73 \%$ ee); however, the reaction rate was significantly lower.

(8) Chiral bis(oxazolines) have frequently been used as ligands in a variety of asymmetric processes. For recent reviews, see: (a) Ghosh, A. K.; Mathivanan, P.; Cappiello, J. Tetrahedron: Asymmetry 1998, 9, 1-45. (b) Johnson, J. S.; Evans, D. A. Acc. Chem. Res. 2000, 33, 325-335.

(9) Davies, I. W.; Gerena, L.; Lu, N.; Larsen, R. D.; Reider, P. J. J. Org. Chem. 1996, 61, 9629-9630.

(10) The influence of carboxylate variable was made on the reaction of $\mathrm{PhCHO}$ with nitromethane, using ligand $\mathbf{2}$ and the indicated $\mathrm{Cu}(\mathrm{II})$ carboxylate: $\mathrm{Cu}(\mathrm{OAc})_{2} \cdot\left(\mathrm{H}_{2} \mathrm{O}\right)(94 \% \mathrm{ee}) ; \mathrm{Cu}(\mathrm{OCHO})_{2} \cdot\left(\mathrm{H}_{2} \mathrm{O}\right)(92 \%$ ee $) ; \mathrm{Cu}(\text { benzoate })_{2}$ (87\% ee); Cu(pivalate) $)_{2}\left(92 \%\right.$ ee); $\mathrm{Cu}(2,4 \text {-dimethoxybenzoate })_{2}(96 \%$ ee) $\mathrm{Cu}$ (4-cyclohexylbutyrate $)_{2}(95 \%$ ee $)$.

(11) For some substrates (e.g., Table 2, entries 1, 2, and 6), lower yields are observed due to subsequent elimination of the nitro alcohol.

(12) (a) Hathaway, B. J. Copper. In Comprehensive Coordination Chemistry; Wilkinson, G., Ed.; Pergamon Press: New York, 1987; Vol. 5, Chapter 53. (b) Hathaway, B. J.; Billing, D. E. Coord. Chem. Rev. 1970, 5, 143-207.

JA037387 